\title{
Altitudinal variation in body size and age structure of the Sauter's frog Rana sauteri in Taiwan
}

\author{
Fu-Hsiung Hsu ${ }^{1 *}$, Yi-Shan Hsieh', Sheng-Hai Wu ${ }^{2}$ and Yeong-Choy Kam ${ }^{3}$
}

\begin{abstract}
Background: The tendency for organisms to be larger in cooler climates, the so-called Bergmann's rule, has been widely observed in endotherms, but it is debatable in ectothermic anurans. Altitudinal variations in body size, age, and growth rate of the Sauter's frog Rana sauteri were investigated with skeletochronology at six sites along the altitudinal gradients from 330 to 2,320 $\mathrm{m}$ in subtropical Taiwan. The aims of this study were to determine whether these life history traits vary with altitude and differ between males and females.

Results: The body size of male $R$. sauteri followed a converse Bergmann's cline; the size decreased with increase in altitude, while no significant altitudinal change was found for females. The size dimorphism was female-biased and became greater at higher altitudes because of the altitudinal decrease in male size. Ages ranged between 1 and 5 years for males and 1 and 6 years for females. There was no significant difference in the age structures between the two sexes, but both sexes had higher average ages at higher-altitude sites. According to von Bertalanffy's model, the growth coefficients decreased with increase in altitude for males but not for females. The annual growth rates were greater for all age classes of females than males, suggesting that growth rate was a major factor underlying body size patterns of both sexes.
\end{abstract}

Conclusions: Growth rate was a major factor underlying body size patterns in both sexes of $R$. sauteri. It could be affected by not only altitudinal temperature gradient but also sex-biased life history traits and environmental factors.

Keywords: Rana sauteri; Skeletochronology; Body size; Altitudinal gradient; Growth rate; Bergmann's rule

\section{Background}

Amphibians have moist naked skin sensitive to subtle changes in surrounding environments, while humidity, rainfall, and temperature have been recognized as the major factors affecting their survival and reproduction (Beattie 1987; Miaud et al. 1999; Ashton 2002). Many endothermic vertebrates with larger body sizes live in cold environments, the so-called Bergmann's rule. It infers that larger body size would have better ability of conserving heat in cold climates which characterize high-latitude and high-altitude regions (Macholán et al. 2008). However, up to now, it still remains controversial whether Bergmann's rule is applicable to body sizes of ectothermic vertebrates like amphibians (Ashton 2002; Adams and Church 2008).

\footnotetext{
* Correspondence: richbear@mail.ncyu.edu.tw

${ }^{1}$ Department of Biological Resources, National Chiayi University, 300

University Road, Chiayi 600, Taiwan

Full list of author information is available at the end of the article
}

Environmental factors determine body size often through their influences on life history traits related with body size (Berven 1982; Miaud et al. 1999; Cvetković et al. 2009). Adult body size of frogs may be affected by many factors such as age at sexual maturity, growth rate, length of activity period, longevity, food availability, and predation (Iturra-Cid et al. 2010; Oromi et al. 2012; Manyak-Davis et al. 2013). Also, the tendency of body size variation in male may differ from that in female within species in the frogs (Zhang et al. 2012; Liao et al. 2013). Altitudes and latitudes may cause a similar temperature effect on amphibians (Morrison and Hero 2003; Sinsch et al. 2010), so it would be necessary to reduce the latitudinal effect in investigating altitudinal effect on body size in amphibians.

Taiwan is situated between $22^{\circ} \mathrm{N}$ and $25^{\circ} \mathrm{N}$ in latitude and $120^{\circ} \mathrm{E}$ and $122^{\circ} \mathrm{E}$ in longitude. Its topography consisted of mountains and hills of which two thirds of its area are above $1,000 \mathrm{~m}$ in altitude. The steep Central Mountain 
Range largely runs along the northeast-southwest axis with the highest peak at nearly 4,000 m above sea level. Rana sauteri is endemic to Taiwan (Frost 2014) and breeds in lotic habitats. It is widely distributed in the Central Mountain Range and its peripheral hills at altitudes from 100 to 3,000 m (Lue et al. 1990; Chou and Lin 1997). Its tadpoles possess an abdominal sucker and an enlarged oral disc, living in fast-flowing streams and grazing on periphyton (Chou and Lin 1997). It provides us an excellent model for analyzing altitudinal variation of its life history traits. Genetic divergences of $R$. sauteri are correlated with horizontal geographical distributions but not with altitudinal distributions (Tanaka-Ueno et al. 1998; Jang-Liaw and Lee 2009; Hsu et al. 2011). In western Taiwan, $R$. sauteri shows an obvious altitudinal cline in life history traits. As temperature decreases with increase in altitude, its breeding season shifts from fall and winter (October to December) to late spring (May), the breeding period is shortened, and the larval period extends from 5 to 12 months (Lai et al. 2002, 2003).

Up to now, little information is available on altitudinal variation in body size and age of anuran species in the subtropical region. This study was intended to investigate the altitudinal variation in body size, age structure, and growth rate of six populations of $R$. sauteri from different altitudinal sites (330 to 2,320 m) at similar latitude in southwestern Taiwan. The objectives were (1) to examine whether body size and age structure varied with altitude, (2) to compare the growth patterns between the sexes at different altitudes, and (3) to examine whether body size and age structure differed between the sexes within the population.

\section{Methods}

\section{Study area and sampling sites}

We selected six sampling sites along the western slope of the Central Mountain Range at altitudes from 330 to 2,320 $\mathrm{m}$ in the Alishan National Scenic Area in southwestern Taiwan (Table 1). The study area has an annual precipitation of 2,500 to $4,500 \mathrm{~mm}$ with the rainy season from May to September, while the precipitation increases with altitude. The average monthly temperature is $21.6^{\circ} \mathrm{C}$ with a range of $15.0^{\circ} \mathrm{C}$ to $27.1^{\circ} \mathrm{C}$ at the lowest site of $330 \mathrm{~m}$ in altitude and $11.6^{\circ} \mathrm{C}$ with a range of $6.2^{\circ} \mathrm{C}$ to $14.6^{\circ} \mathrm{C}$ at the highest site of $2,320 \mathrm{~m}$.

\section{Sampling method}

At each of the sampling sites, we set a 50-m transect strip and caught monthly adult frogs along moving water areas of ravine streams from March 2005 to December 2006. During the breeding season when calling males aggregated, we visited 630-, 1,380-, and 2,320-m sites weekly and recorded the numbers of frogs, freshly deposited egg masses, and larval developmental stages to determine the period of breeding activities (Morrison et al. 2004; Cvetković et al. 2009). A total of 1,405 males and 145 females of $R$. sauteri were caught during the study period.

We anesthetized the frogs with MS-222 (Kusano et al. 1995). For each individual, snout-vent length (SVL) and hind limb length were measured to the nearest $0.1 \mathrm{~mm}$ with digital calipers, and sex was determined according to body size and the presence of the nuptial pad (Lai et al. 2003). We marked all individuals with the toe-clipping method and then released them in situ. We also clipped the three phalanges of the fourth toe of the left hind limb and preserved them in a 10\% neutral buffered formalin water solution for at least 5 days for the skeletochronological study (Sagor et al. 1998; Lai et al. 2005).

\section{Skeletochronology}

A total of 162 males and 90 females were used for skeletochronological analysis. We selected at least 15 females and 15 males at each of the sampling sites for age determination with skeletochronology. Exceptions were those at the 2,100-m and 2,320-m sites where a few adult females were collected. The average SVLs of females and males were not significantly different ( $t$-test, all $p>0.05$ ) between the captured frogs and those latter selected for skeletochronological analyses at each of the sampling sites.

The fixed phalanges were washed with tap water, decalcified in 3\% nitro acid for at least $3 \mathrm{~h}$, and then shook in dilution water overnight. For each of the phalanges, the mid-diaphyseal part was cut into 10 - to $20-\mu \mathrm{m}$-thick transverse sections with a freezing microtome (Rozenblut and Ogielska 2005). The sections were immediately stained with Ehrlich's hematoxylin for $15 \mathrm{~min}$, rinsed with distilled

Table 1 Altitudes, breeding season, larval period, breeding activity period (AP), and number of Rana sauteri

\begin{tabular}{llllllll}
\hline Sampling sites & Latitude $(\mathbf{N})$ & Longitude (E) & Altitude $(\mathbf{m})$ & Breeding season & Larval period & Males/females & AP (weeks) \\
\hline $330 \mathrm{~m}$ & $23^{\circ} 25^{\prime} 42^{\prime \prime}$ & $120^{\circ} 36^{\prime} 43^{\prime \prime}$ & 330 & October to December & October to February & $120 / 35$ & \\
$630 \mathrm{~m}$ & $23^{\circ} 26^{\prime} 54^{\prime \prime}$ & $120^{\circ} 38^{\prime} 53^{\prime \prime}$ & 630 & October to December & October to March & $732 / 41$ & 11 \\
$970 \mathrm{~m}$ & $23^{\circ} 29^{\prime} 02^{\prime \prime}$ & $120^{\circ} 41^{\prime} 06^{\prime \prime}$ & 970 & October to November & October to March & $169 / 24$ \\
$1,380 \mathrm{~m}$ & $23^{\circ} 28^{\prime} 55^{\prime \prime}$ & $120^{\circ} 42^{\prime} 55^{\prime \prime}$ & 1,380 & October to November & October to March & $242 / 25$ & 6 \\
$2,100 \mathrm{~m}$ & $23^{\circ} 31^{\prime} 10^{\prime \prime}$ & $120^{\circ} 48^{\prime} 23^{\prime \prime}$ & 2,100 & May to June & Year round & $54 / 8$ & $88 / 12$ \\
$2,320 \mathrm{~m}$ & $23^{\circ} 30^{\prime} 27^{\prime \prime}$ & $120^{\circ} 49^{\prime} 04^{\prime \prime}$ & 2,320 & May to June & Year round & 3 \\
\hline
\end{tabular}

The values were taken from the six sampling sites in southwestern Taiwan. 
water, mounted in a drop of $50 \%$ glycerol on a glass microscope slide, and sealed with blank glue for skeletonchronological analyses. At least three clear sections with smaller medullar cavities per specimen were photographed under a microscope with a CCD camera and transferred to digital images on a computer screen.

The lines of arrested growth (LAGs) were counted to estimate the age of each individual (Figure 1). Specimens were examined independently by two observers. Each slide with the label covered was read twice by the observers (Morrison et al. 2004; Lai et al. 2005). The endosteal resorption from the inner surface of the bone could completely destroy LAGs, resulting in age determination error (Sagor et al. 1998; Rozenblut and Ogielska 2005). Following the protocol of Lai et al. (2005), we compared the major axis of the innermost LAG of each section with the mean of juveniles' LAG without resorption. When the major axis of the innermost LAG of an adult was significantly greater than the mean LAG of juveniles without resorption, we considered that the resorption had occurred and a LAG was added for that adult. Endosteal resorption of the innermost LAG was observed in $38.9 \%$ of males and $18.9 \%$ of females but did not affect the accuracy of age estimation in this study. The major axes of all LAGs were measured on the digital images with Motic Images plus 2.0. False lines and double lines were rarely observed, but we counted the double line as one LAG (Olgun et al. 2005; Iturra-Cid et al. 2010).

\section{Growth rate estimation}

To describe growth rates and to compare the rates among frogs among different altitudes, we used von Bertalanffy's model (von Bertalanffy 1938, 1957) with a nonlinear regression procedure: $\mathrm{SVL}_{t}=\mathrm{SVL}_{\max } \times\left(1-e^{-k t+b}\right)$, where $\mathrm{SVL}_{t}$

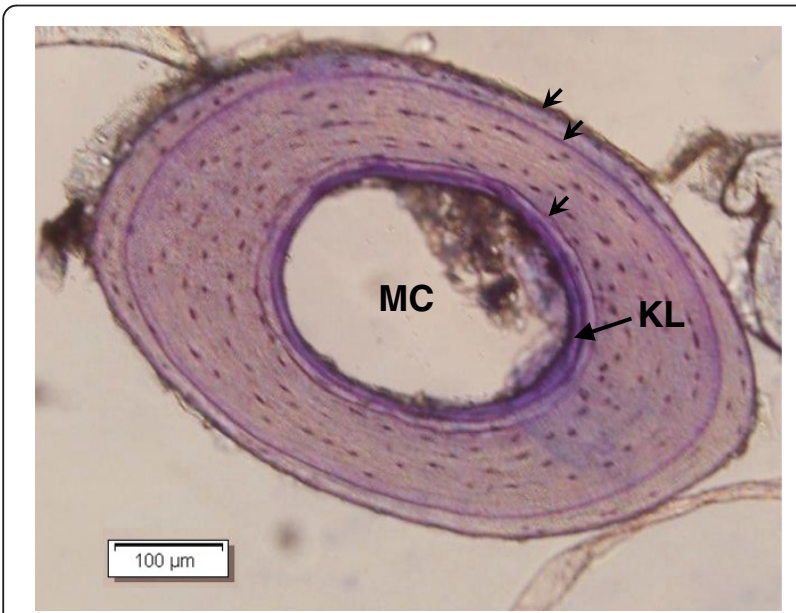

Figure 1 A cross section of a phalange of Rana sauteri. Arrows indicate the lines of arrested growth ( $L A G s)$. $K L$ represents

Kastschenko line, the interface between endosteal and periosteal zones. $\mathrm{MC}=$ marrow cavity is SVL at age $t, \mathrm{SVL}_{\max }$ is estimated asymptotic SVL, $k$ is a growth coefficient relating to rate of decline in growth when frogs attain the maximum SVL, and $b$ is constant (Miaud et al. 2001; Leclair et al. 2005; Lu et al. 2006; Ma et al. 2009b). The starting point of the growth curve was set at the metamorphosis. For this, we used the mean SVL $13.46 \pm 0.72 \mathrm{~mm}(n=37)$ of the tadpoles at Gosner stages 42 to 45 captured at the $630-\mathrm{m}$ site. Annual growth rates $(R)$ were calculated as $R=d \mathrm{SVL} / d t=k \times\left(\mathrm{SVL}_{\max }-\mathrm{SVL}_{t}\right)$ (Cvetković et al. 2009; Ma et al. 2009a; Iturra-Cid et al. 2010).

\section{Statistical analyses}

Sexual dimorphism index (SDI) (Lovich and Gibbons 1992) was used to describe the sexual size dimorphism for each population. It was calculated with the formula: $\mathrm{SDI}=$ (Mean length of the larger sex/Mean length of the smaller sex) -1 . The SDI obtained was arbitrarily defined as positive when females are larger than males. Student's $t$-test was used to test the significant level in difference of body sizes between males and females in each of the populations. Inter-populational comparisons of mean SVLs were conducted with ANOVA. It was followed by Bonferroni post hoc multiple comparisons when there was a significant difference among populations in body size. Age class distributions were compared between two sexes with chi square test. For comparison of median ages among sites, we used the Kruskal-Wallis test and followed by Dunnett's post hoc multiple comparisons. The analysis of covariance (ANCOVA) was used to detect whether the body size was still statistically significant between the two sexes or among populations after the age covariate was removed. Normality was checked by the Kolmogorov-Smirnov test when parametric tests were used. All probabilities were twotailed, and the significant level was set at $p<0.05$. The software Statistica 7.0 (StatSoft Inc., Tulsa, OK, USA) was used for the analysis.

\section{Results}

\section{Breeding season and breeding activity period}

We captured and marked 62 to 773 adult frogs (Table 1) at the six sampling sites. Calling and aggregation of mature adults were observed in early October at the 330-, 630-, 970-, and 1,380-m sites. Breeding seasons ended in late November at the 970- and 1,380-m sites but in December at the 330- and 630-m sites. However, tadpoles were found in the streams from October to following February at the four sites. At the 2,100- and 2,320- sites, the breeding season occurred from May to June, but tadpoles were observed in the water all year round. Breeding activity period decreased from 11 weeks at the low-altitude sites to 3 weeks at the high-altitude sites (Table 1). More than ten adult frogs could be found 
across the 50-m strip weekly at each site during the breeding activity period.

\section{Altitudinal variation in adult age and body size}

The ages ranged between 1 and 5 years for males and between 1 and 6 years for females. The predominant age classes were 2 to 3 years ( $71 \%$ in the males and $63 \%$ in the females). Male and female frogs at the $330-\mathrm{m}$ site did not exceed 3 years old, while no 1-year-old frog was observed at the 2,100- and 2,320-m sites (Figure 2). The median ages of both sexes significantly differed among populations at the different altitudes (Kruskal-Wallis test: males, $H=30.6, p<0.01$; females, $H=18.5, p=0.02$ ). Males at the 2,100- and 2,320-m sites were significantly older than those at the three sites below $1,000 \mathrm{~m}$ in altitude (Dunnett's post hoc test, $p<0.05)$. Females inhabiting at the 2,320-m site were also significantly older than those at the 330- and 630-m sites (Table 2).

Average SVLs of males differed significantly among the six sites $\left(F_{5,156}=32.6, p<0.01\right)$. Male at higher altitudes were significantly smaller than those at lower altitudes (Bonferroni post hoc test, $p<0.01$, Table 2), but no significant difference was found between neighboring sites. However, the average SVLs of females were not significantly different among different altitudes $\left(F_{5,84}=1.37\right.$, $p=0.244)$. ANCOVAs revealed that age had a significant effect on body size for both males $\left(F_{1,155}=125.82, p<0.01\right)$ and females $\left(F_{1,83}=294.49, p<0.01\right)$. After adjusted for age difference, size differences in males among different sites became more significant $\left(F_{5,155}=81.21, p<0.01\right)$, with significant differences found in 13 of 15 Bonferroni post hoc comparisons. Female SVLs also exhibited significant
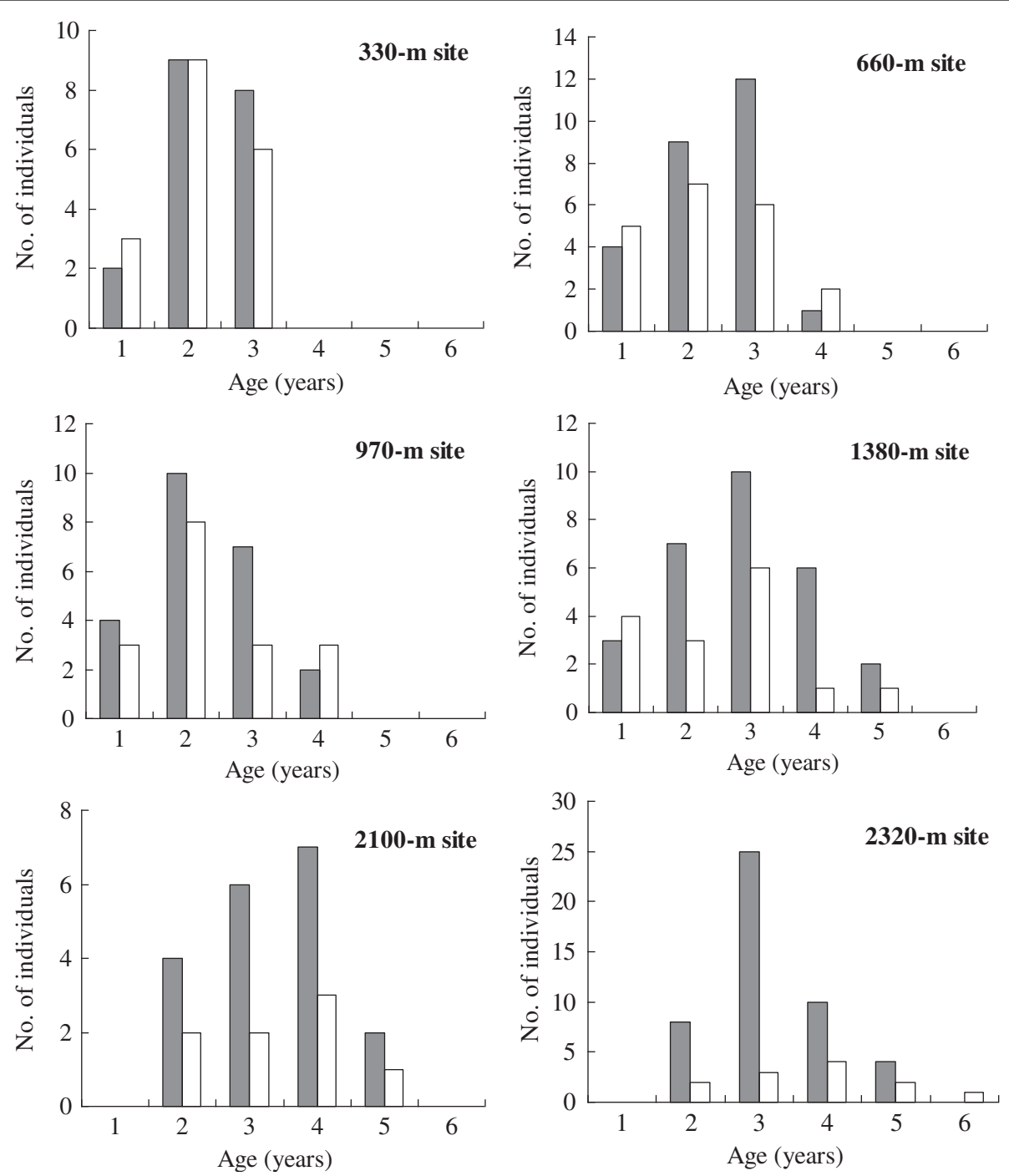

Figure 2 Age distribution of adult Rana sauteri at six sampling sites. Gray bars represent males and white bars represent females. 
Table 2 SVL, SDI, and estimated ages of adult Rana sauteri at six altitudinal sites

\begin{tabular}{|c|c|c|c|c|c|c|c|}
\hline \multirow[t]{2}{*}{ Sampling sites } & \multicolumn{4}{|l|}{ SVL (mm) } & \multirow[t]{2}{*}{ SDI } & \multicolumn{2}{|c|}{ Mean age (year) } \\
\hline & Males & $n$ & Females & $n$ & & Males & Females \\
\hline $330 \mathrm{~m}$ & $43.85 \pm 2.03 \mathrm{a}$ & 19 & $49.93 \pm 3.01$ & 18 & 0.139 & $2.32 \pm 0.67 a$ & $2.17 \pm 0.71 \mathrm{a}$ \\
\hline $630 \mathrm{~m}$ & $42.02 \pm 2.10 \mathrm{ab}$ & 26 & $50.09 \pm 3.50$ & 20 & 0.192 & $2.38 \pm 0.80 \mathrm{a}$ & $2.25 \pm 0.97 \mathrm{a}$ \\
\hline $970 \mathrm{~m}$ & $40.42 \pm 2.29 b c$ & 23 & $48.51 \pm 3.09$ & 17 & 0.200 & $2.30 \pm 0.88 a$ & $2.35 \pm 1.00 \mathrm{ab}$ \\
\hline $1,380 \mathrm{~m}$ & $40.11 \pm 2.68 c$ & 28 & $51.17 \pm 4.54$ & 15 & 0.276 & $2.89 \pm 1.10 \mathrm{ab}$ & $2.47 \pm 1.19 a b$ \\
\hline $2,100 \mathrm{~m}$ & $38.75 \pm 1.51 \mathrm{~cd}$ & 19 & $51.39 \pm 3.26$ & 8 & 0.326 & $3.37 \pm 0.96 b$ & $3.38 \pm 1.06 \mathrm{ab}$ \\
\hline \multirow[t]{3}{*}{$2,320 \mathrm{~m}$} & $37.32 \pm 2.03 d$ & 47 & $50.91 \pm 3.05$ & 12 & 0.364 & $3.21 \pm 0.83 b$ & $3.75 \pm 1.22 b$ \\
\hline & $F_{5,156}=32.62$ & & $F_{5,84}=1.37$ & & & $H=30.563$ & $H=18.48$ \\
\hline & $p<0.001$ & & $p=0.2439$ & & & $p<0.001$ & $p=0.0024$ \\
\hline
\end{tabular}

Values in descending order are mean \pm SD. The means of SVLs of the populations were analyzed with ANOVA followed by Bonferroni's post hoc test. The median ages were compared with Kruskal-Wallis test followed by Dunnett's post hoc test. Values sharing the same letters (a to d) were not significantly different $(p>0.05)$ with post hoc pairwise comparisons. SVL, snout-vent length; SDI, index of sexual size dimorphism; $n$, sample size.

difference among sites $\left(F_{5,83}=11.48, p<0.01\right)$. Pairwise comparisons showed that it was mainly due to smaller female body sizes at the $970-\mathrm{m}$ site than those at higher-altitude sites (Bonferroni post hoc test, $p<0.01$ ).

\section{Sexual differences in adult age and body size}

The age distribution was not significantly different between the two sexes when all sites were combined $\left(\chi^{2}=9.02, p=0.11\right)$ or each of the sites was examined independently (Figure 2). The average SVL was $50.16 \pm 3.49 \mathrm{~mm}(n=90)$ for females and $39.93 \pm 3.04 \mathrm{~mm}$ $(n=162)$ for males, while the average SVL of females was significantly larger than that of males at each site ( $t$-test, all $p<0.01)$. ANCOVAs revealed that the sexual size dimorphism remained significant when the effect of age was controlled. The SDI increased from 0.139 at the lowestaltitude site to 0.364 at the highest-altitude site (Table 2), resulted mainly from decreasing in male size with increase in altitude.

\section{Growth pattern}

The average SVLs of both sexes increased with increase in age (Figure 3). According to von Bertalanffy's model, the predicted asymptotic body size $\left(L_{\max }\right)$ of females was larger than that of males at each site (Table 3). The predicted asymptotic body sizes were higher than the maximum SVLs of males and females, suggesting that the frogs could have a potential to grow even much larger. The growth coefficient, $k$, that describes how quickly the asymptote is reached had a lower value for both sexes at high altitudes (2,100- and 2,320-m sites). The $k$ values of males tended to decrease with increase in altitude but showed a great variability in females. The annual growth rates for age classes of females were larger than those of males (Table 4). For the males, annual growth rates at low altitudes were usually larger than those at high altitudes, but for the females, they were less consistent among the altitudes. In general, annual growth rates of
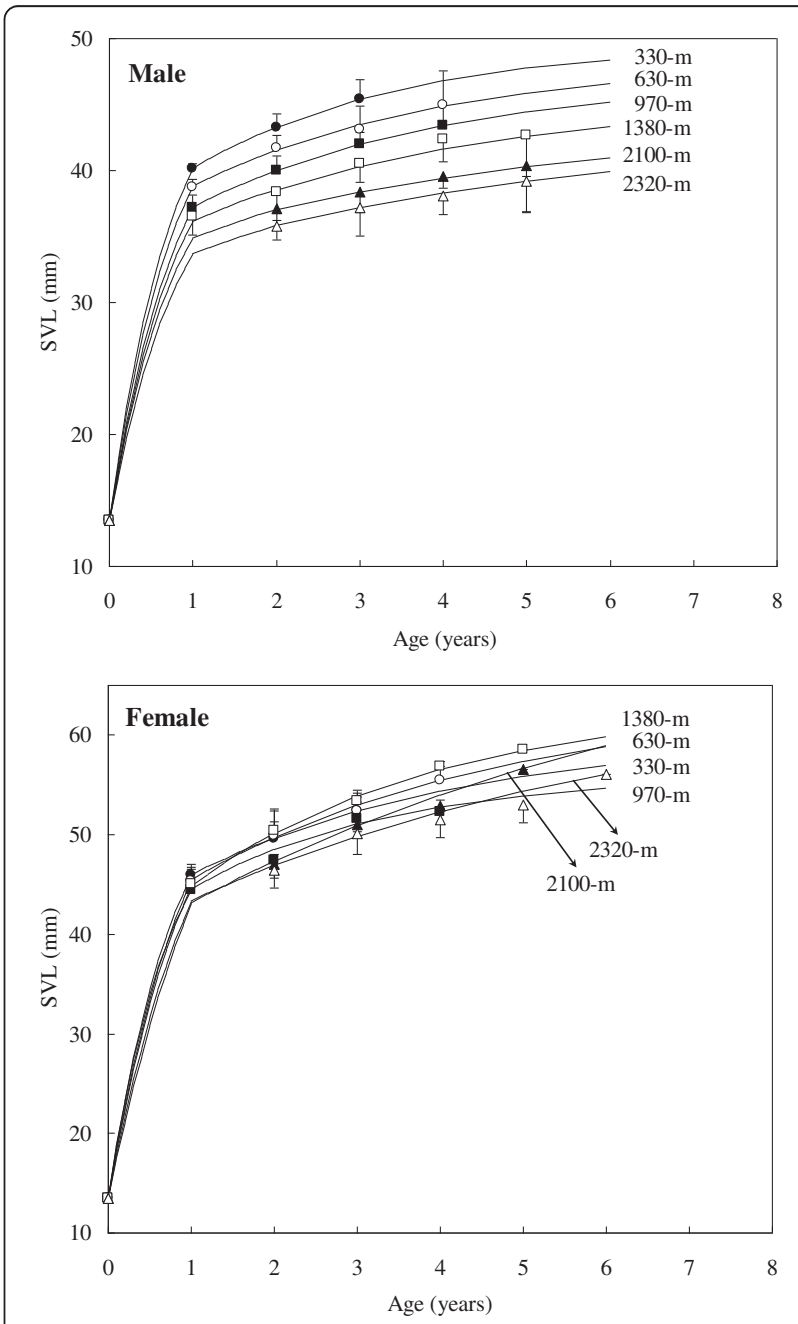

Figure 3 Age-size relationship for the studied populations. Growth curves best fitted to von Bertalanffy's model for males (top) and females (bottom) of Rana sauteri sampled at six altitudinal sites in southwestern Taiwan. Vertical bars depict standard deviations. Black circle, $330 \mathrm{~m}$; white circle, $630 \mathrm{~m}$; black square, $970 \mathrm{~m}$; white square, 1,380 m; black triangle, 2,100 m; white triangle, 2,320 m. 
Table 3 Growth parameters of von Bertalanffy's model for Rana sauteri at six altitudinal sites, southwestern Taiwan

\begin{tabular}{|c|c|c|c|c|c|c|}
\hline \multirow[t]{2}{*}{ Sampling sites } & \multicolumn{3}{|l|}{ Males } & \multicolumn{3}{|l|}{ Females } \\
\hline & $\mathrm{SVL}_{\max (\mathrm{mm})}$ & $k$ & $b$ & $S V L_{\max (\mathrm{mm})}$ & $k$ & $b$ \\
\hline $330 \mathrm{~m}$ & 49.68 & 0.40 & -1.25 & 60.23 & 0.30 & -1.15 \\
\hline $630 \mathrm{~m}$ & 48.36 & 0.34 & -1.28 & 63.61 & 0.27 & -0.99 \\
\hline $970 \mathrm{~m}$ & 47.04 & 0.33 & -1.23 & 55.98 & 0.43 & -1.16 \\
\hline $1,380 \mathrm{~m}$ & 45.58 & 0.29 & -1.29 & 63.40 & 0.33 & -0.90 \\
\hline $2,100 \mathrm{~m}$ & 43.80 & 0.22 & -1.43 & 73.53 & 0.15 & -0.74 \\
\hline $2,320 \mathrm{~m}$ & 43.49 & 0.19 & -1.35 & 64.75 & 0.18 & -0.93 \\
\hline
\end{tabular}

both sexes gradually decreased with increase in age (Table 4).

\section{Discussion}

The results showed that the body size variation in $R$. sauteri at six altitudinal sites exhibited different patterns between the sexes. The body size of males exhibited a converse Bergmann cline with the individuals at higher altitudes being smaller than those at lower ones, while no consistent altitudinal trend was found for females. Up to now, only a few studies on amphibians reported the different sexual trends in altitudinal variation in body size. Ashton (2002) reviewed the body size variation in amphibians and indicated that 23 of 34 species conformed to the pattern expected by Bergmann's rule, whereas 11 species exhibited a converse of Bergmann's cline. Recently, positive correlation between body size and altitude was reported for Rana swinhoana (Lai et al. 2005), Rana chensinensis (Lu et al. 2006; Ma et al. 2009b), Pleurodema thaul (Iturra-Cid et al. 2010), Hyla annectans chuanxiensis (Liao and Lu 2010), and Rana limnocharis (Liu et al. 2012), whereas a converse Bergmann cline was reported for Rana muscosa (Matthews and Miaud 2007), Nanorana parkeri (Ma et al. 2009a), and Rana nigromaculata (Liao et al. 2010). However, N. parkeri showed a steeper altitudinal decrease in female size, whereas no clear altitudinal relationship was detected for males (Zhang et al. 2012).

In this study, the different trends of body size in relation to altitudes between the two sexes of $R$. sauteri suggested that the temperature gradient was not only the factor affecting the body size variation in amphibians (Cvetković et al. 2009). Various life history traits and environmental factors may also affect the variation. Liao and $\mathrm{Lu}$ (2012) suggested that the starting size (metamorphic size), annual growth rate, and the length of time individuals spent on growing (age) could affect the body size of ectothermic animals such as frogs. A given adult size could be achieved through changing in any one of the above factors or their combination. An individual which metamorphoses at a larger size had a better chance to survive in the following terrestrial stage and reach larger body size at sexual maturity (Altwegg and Reyer 2003; Marangoni and Tejedo 2008). Also, the growth rates usually differ before and after achieving sexual maturity. It is a general life history strategy for ectothermic organisms that individuals tend to devote more energy into growth before sexual maturity to reach larger body sizes. When they reach maturity, the growth slows down and more energy was devoted into reproduction (Iturra-Cid et al. 2010; Sinsch et al. 2010). Harsher conditions at higher-altitude sites in terms of food resource, climate, and activity period may constrain reproductive and growth potentials of animals (Dmitriew 2011). Our study showed that small metamorphic sizes and slow growth rates at higher altitudes could result in smaller body sizes for adult male frogs, inducing a converse Bergmann's cline. However, the ontogenetic trajectory of females may be different from that of males in anurans (Zhang and Lu 2013). At higher altitudes, when females have longer life-span with higher growth rate after sexual maturity and delay in reproduction (Liao and $\mathrm{Lu}$ 2012), these will compensate the low-temperature effects, resulting in no trend of obvious decrease in body size along the altitudinal gradients.

We found that $R$. sauteri at higher altitudes lived longer than those at lower altitudes, similar to that observed in

Table 4 Annual growth rates $(R)$ of different age classes of Rana sauteri at six altitudinal sites

\begin{tabular}{|c|c|c|c|c|c|c|c|c|c|c|c|c|}
\hline \multirow[b]{3}{*}{ Ages } & \multicolumn{12}{|c|}{$R$ (mm/year) } \\
\hline & \multicolumn{6}{|l|}{ Males } & \multicolumn{6}{|c|}{ Females } \\
\hline & $330 \mathrm{~m}$ & $630 \mathrm{~m}$ & $970 \mathrm{~m}$ & $1,380 \mathrm{~m}$ & $2,100 \mathrm{~m}$ & $2,320 \mathrm{~m}$ & $330 \mathrm{~m}$ & $630 \mathrm{~m}$ & $970 \mathrm{~m}$ & $1,380 \mathrm{~m}$ & $2,100 \mathrm{~m}$ & $2,320 \mathrm{~m}$ \\
\hline 1 & 3.82 & 3.24 & 3.28 & 2.61 & & & 4.22 & 4.87 & 4.93 & 6.08 & & \\
\hline 2 & 2.56 & 2.26 & 2.35 & 2.08 & 1.47 & 1.48 & 3.14 & 3.66 & 3.68 & 4.30 & 3.90 & 3.30 \\
\hline 3 & 1.71 & 1.77 & 1.67 & 1.46 & 1.20 & 1.21 & 2.33 & 2.99 & 1.86 & 3.32 & 3.31 & 2.64 \\
\hline 4 & & 1.16 & 1.21 & 0.92 & 0.93 & 1.04 & & 2.17 & 1.56 & 2.16 & 3.04 & 2.40 \\
\hline 5 & & & & 0.84 & 0.76 & 0.83 & & & & 1.60 & 2.50 & 2.12 \\
\hline 6 & & & & & & & & & & & & 1.57 \\
\hline Mean & 2.70 & 2.11 & 2.13 & 1.58 & 1.09 & 1.14 & 3.23 & 3.42 & 3.01 & 3.49 & 3.19 & 2.41 \\
\hline SD & 1.06 & 0.88 & 0.90 & 0.76 & 0.31 & 0.28 & 0.95 & 1.14 & 1.59 & 1.79 & 0.58 & 0.64 \\
\hline
\end{tabular}


many species of anurans (Zhang and Lu 2012). Also, the annual growth rates of males were larger at lower altitudes than those at higher altitudes perhaps due to the longer activity period at the low altitudes. There is a positive correlation between the annual growth rate and the activity period (Cvetković et al. 2009). Though the male R. sauteri had higher mean age class at higher altitudes, the small age difference among the sites and low average annual growth rate after sexual maturity $(1.2 \mathrm{~mm} /$ year after 2 years old $)$ could not reverse the trend of body size decrease with altitude. Lai et al. (2002) showed that the mean SVLs of metamorphosed froglets of $R$. sauteri were $14.42 \mathrm{~mm}$ $(n=142)$ and $11.84 \mathrm{~mm}(n=26)$ in Chitou $(1,200 \mathrm{~m})$ and Mienyueh $(2,300 \mathrm{~m})$, respectively. The metamorphosed body size was significantly smaller at the high altitudes than those at low altitudes. The variation in metamorphosed body size, slight age difference, and low annual growth rate might cause decreasing body sizes with increase in altitude for male $R$. sauteri, depicting the converse Bergmann's cline.

Variation in growth rate has been observed in response to various environmental factors, such as food availability, predation risk, competition, and population density (Dmitriew 2011). Predation risk usually induces the variations of life history traits such as body size (Ashton et al. 2000; Laurila et al. 2002; Manyak-Davis et al. 2013). Male frogs exhibit conspicuous behaviors and are prone to predators when they aggregate in large chorusing groups during breeding (Tsiora and Kyriakopoulou-Sklavounou 2002). Furthermore, predation risk in terms of diversity and density of predators should be greater at lower altitudes than at higher altitudes (Morrison and Hero 2003). Also, smaller males and juvenile frogs were more vulnerable to predation (Zug 1993; Matthews and Miaud 2007). The results of such altitudinal and size differences in the predation may increase the survival rate of males with larger body size at low altitudes. However, more data are needed for confirmation. It may be stated that body size variation is a morphological adaptation associated with escaping behavior in response to predation (Dmitriew 2011). The population sizes of $R$. sauter $i$ at the six sites decreased with an increase in altitude. Mark-recapture data analysis with the JollySeber method (Krebs 1999) produced the highest estimated weekly population size of 577 frogs at the 630-m site, 224 frogs at the 1,380-m site, and 80 frogs at the 2,320-m site (YSH, unpublished data). High population densities were found at lower-altitude sites, and thus, frequent male-male aggressions might confer mating advantage of large males and enhanced the strength of sexual selection (Knell 2009).

Female body size, however, did not differ among populations across altitudes except at the 970-m site in which females were significantly smaller than those at higheraltitude sites. The annual growth rates of females had no clear trend with altitude, but the mean growth rates were larger than those of males. Female anuran fecundity is known to correlate with body size, because the anurans display indeterminate growth, leading to faster growth rate and delayed reproduction for females (Monnet and Cherry 2002). The higher growth rate after sexual maturity and longer lifespan at higher-altitude site might result in Bergmann's cline (Liao and Lu 2012). However, though the high annual growth rate might cause larger body size for the females, the small disparity in the mean ages among the altitudinal sites might obscure the trend of body size variation along the altitudinal gradients.

The decision how to allocate marginal resources into reproduction and growth may have important effects on associated life history parameters such as body size (Lardner and Loman 2003). Changes in body composition at maturation may determine the outcome of trade-offs between reproduction and survival or between early and late reproductions (Dmitriew 2011). Amphibians tend to invest less in reproduction towards higher latitudes and prolong their growth periods (Morrison and Hero 2003). In addition, it is energetically cheaper to produce sperm than ova in anurans. Fecundity selection may favor larger females to increase the subsequence reproductive output at higher latitudes. The sexspecific phenotypic variation exhibited by $R$. sauteri may be associated with different sexes exposed to different pressures along altitudinal gradients and reacting by modifying their life histories in a different way.

\section{Conclusions}

The results of this study showed that the tendency of body size variation in $R$. sauteri along altitudes exhibited different patterns between the two sexes. For better survival and reproductive success, male and female animals under different physiological constrains and reproductive investment strategies may develop different adaptive characters in their life history traits to increase their fitness. Even a similar environmental factor may impose different selective pressure that shapes the life history traits between the sexes (Ma et al. 2009b; Zhang et al. 2012; Liao et al. 2013). In this study, growth rate was a major factor underlying body size patterns in both sexes of $R$. sauteri and affected by not only altitudinal temperature gradient but also sex-biased life history traits and environmental factors.

\section{Abbreviations}

SVL: snout-vent length; LAGs: lines of arrested growth; $R$ : annual growth rate; SDI: sexual dimorphism index; AP: breeding activity period.

\section{Competing interests}

The authors declare that they have no competing interests. 


\section{Authors' contributions}

$\mathrm{FHH}$ conceived the study and performed the data collection, the statistical analyses, and drafting of the manuscript. YSH participated in the design of the study and carried out the fieldwork and skeletochronological study. SHW and YCK contributed in the statistical analyses, drafting of the manuscript, and study coordination. All authors read and approved the final manuscript.

\section{Acknowledgements}

We heartily appreciate Drs. Chu-Fa Tsai and Su-Ju Lai for their constructive suggestions on the study and comments on the manuscript. We thank Chun-Fu Lin and Ya-Fen Tsai for assisting in the skeletochronology, Rui-Yuan Gu and Ming-Chieh Lin for assisting in sampling and survey in the field, and two anonymous referees for providing valuable comments. This study was supported in part by a grant from the Council of Agriculture, Taiwan.

\section{Author details}

${ }^{1}$ Department of Biological Resources, National Chiayi University, 300 University Road, Chiayi 600, Taiwan. ${ }^{2}$ Department of Life Sciences, National Chung Hsiung University, Taichung 402, Taiwan. ${ }^{3}$ Department of Life Sciences, Tunghai University, Taichung 407, Taiwan.

Received: 16 May 2014 Accepted: 2 September 2014

\section{Published online: 10 September 2014}

\section{References}

Adams DC, Church JO (2008) Amphibians do not follow Bergmann's rule. Evolution 62:413-420

Altwegg R, Reyer HU (2003) Patterns of natural selection on size at metamorphosis in water frogs. Evolution 57:872-882

Ashton KG (2002) Do amphibians follow Bergmann's rule? Can J Zoolog 80:708-716 Ashton KG, Tracy MC, de Queiroz A (2000) Is Bergmann's rule valid for mammals? Am Nat 156:390-415

Beattie RC (1987) The reproductive biology of common frog (Rana temporaria) populations from different altitudes in northern England. J Zool 211:387-398

Berven KA (1982) The genetic basis of altitudinal variation in the wood frog Rana sylvatica. I. An experimental analysis of life history traits. Evolution 36:962-983

Chou WH, Lin JY (1997) Geographical variations of Rana sauteri (Anura: Ranidae) in Taiwan. Zool Stud 36:201-221

Cvetković D, Tomašević N, Ficetola GF, Crnobrnja-Isailović J, Miaud C (2009) Bergmann's rule in amphibians: combining demographic and ecological parameters to explain body size variation among populations in the common toad Bufo bufo. J Zool Syst Evol Res 47:171-180

Dmitriew CM (2011) The evolution of growth trajectories: what limits growth rate? Biol Rev 86:97-116

Frost DR (2014) Amphibian Species of the World: an Online Reference, version 6.0. American Museum of Natural History, New York. Electronic database accessible at http://research.amnh.org/vz/herpetology/amphibia/

Hsu FH, Lin RS, Wu SH, Tsai CF (2011) Taxonomic status of the Rana sauteri complex: discordance between genetic and morphological traits. Herpetol J 21:169-179

Iturra-Cid M, Ortiz JC, Ibargüengoytía R (2010) Age, size, and growth of the Chilean frog Pleurodema thaul (Anura: Leiuperidae): latitudinal and altitudinal effects. Copeia 2010:609-617

Jang-Liaw NH, Lee TH (2009) Intraspecific relationships of populations of the brown frog Rana sauteri (Ranidae) on Taiwan, inferred from mitochondrial cytochrome $b$ sequences. Zool Sci 26:608-616

Knell RJ (2009) Population density and the evolution of male aggression. J Zool (Lond) 278:83-90

Krebs CJ (1999) Ecological methodology, 2nd edition. Addison-Welsey Educational Publishers, Inc., Menlo Park

Kusano T, Fukuyama K, Miyashita N (1995) Age determination of the stream frog, Rana sakuraii, by skeletochronology. J Herpetol 29:625-628

Lai SJ, Kam YC, Hsu FH, Lin YS (2002) Elevational effects on the growth and development of tadpoles of Sauter's frog Rana sauteri Boulenger in Taiwan. Acta Zool Taiwan 13:11-20

Lai SJ, Kam YC, Lin YS (2003) Elevational variation in reproductive and life history traits of Sauter's frog Rana sauteri Boulenger, 1909 in Taiwan. Zool Stud 42:193-202

Lai YC, Lee TH, Kam YC (2005) A skeletochronological study on a subtropical, riparian ranid (Rana swinhoana) from different elevations in Taiwan. Zool Sci 22:653-658
Lardner B, Loman J (2003) Growth or reproduction? Resource allocation by female frogs Rana temporaria. Oecologia 137:541-546

Laurila A, Pakkasmaa S, Crochet PA, Merilä J (2002) Predator-induced plasticity in early life history and morphology in two anuran amphibians. Oecologia 132:524-530

Leclair MH, Leclair R, Jr, Gallant J (2005) Application of skeletochronology to a population of Pelobates cultripes (Anura: Pelobatidae) from Portugal. J Herpetol 39:199-207

Liao WB, Lu X (2010) Age structure and body size of the Chuanxi tree frog Hyla annectans chuanxiensis from two different altitudes in Sichuan (China). Zool Anz 248:255-263

Liao WB, Lu X (2012) Adult body size $=f$ (initial size + growth rate $\times$ age): explaining the proximate cause of Bergman's cline in a toad along altitudinal gradients. Evol Ecol 26:579-590

Liao WB, Zhou CQ, Yang ZS, Hu JC, Lu X (2010) Age, size and growth in two populations of the dark-spotted frog Rana nigromaculata at different altitudes in southwestern China. Herpetol J 20:77-82

Liao WB, Zeng Y, Yang DJ (2013) Sexual size dimorphism in anurans: roles of mating system and habitat types. Front Zool 10:65

Liu YH, Zeng Y, Liao WB, Zhou CQ, Mi ZP, Mao M, Chen L (2012) Altitudinal variation in body size in the rice frog (Rana limnocharis) in southwestern China. Acta Herpetol 7:57-68

Lovich JE, Gibbons JW (1992) A review of techniques for quantifying sexual size dimorphism. Growth Dev Aging 56:269-281

Lu X, Li B, Liang JJ (2006) Comparative demography of a temperate anuran, Rana chensinensis, along a relatively fine elevational gradient. Can J Zoolog 84:1789-1795

Lue KY, Lin CY, Jung KS (1990) Wildlife data bank of Taiwan, (1) amphibians (II). Ecological Research of the Council of Agriculture, Taipei (in Chinese)

Ma X, Lu X, Merilä J (2009a) Altitudinal decline of body size in a Tibetan frog. J Zool 279:364-371

Ma X, Tong L, Lu X (2009b) Variation of body size, age structure and growth of a temperate frog, Rana chensinensis, over an altitudinal gradient in northern China. Amphibia-Reptilia 30:111-117

Macholán M, Mikula O, Vohralík V (2008) Geographic phenetic variation of two eastern-Mediterranean non-commensal mouse species, Mus macedonicus and M. cypriacus (Rodentia: Muridae) based on traditional and geometric approaches to morphometrics. Zool Anz 247:67-80

Manyak-Davis A, Bell TM, Sotka EE (2013) The relative importance of predation risk and water temperature in maintaining Bergmann's rule in a marine ectotherm. Am Nat 182:347-358

Marangoni F, Tejedo M (2008) Variation in body size and metamorphic traits of Iberian spadefoot toads over a short geographic distance. J Zool 275:97-105

Matthews KR, Miaud C (2007) A skeletochronological study of the age structure, growth, and longevity of the mountain yellow-legged Frog, Rana muscosa, in the Sierra. Copeia 2007:986-993

Miaud C, Guyetant R, Elmberg J (1999) Variations in life-history traits in the common frog Rana temporaria (Amphibia: Anura): a literature review and new data from the French Alps. J Zool 249:61-73

Miaud C, Andreone F, Ribéron A, Michelis S, Clima V, Castanet J, Francillon-Vieillot H, Guyétant R (2001) Variations in age, size at maturity and gestation duration among two neighboring populations of the alpine salamander (Salamandra lanzai). J Zool 254:51-260

Monnet J, Cherry MI (2002) Sexual size dimorphism in anurans. Proc R Soc Lond B Biol Sci 269:2301-2307

Morrison C, Hero JM (2003) Geographic variation in life history characteristics of amphibians: a review. J Anim Ecol 72:270-279

Morrison C, Hero JM, Browning J (2004) Altitudinal variation in the age at maturity, longevity, and reproductive lifespan of anurans in subtropical Queensland. Herpetologica 60:34-44

Olgun K, Uzum N, Avci A, Miaud C (2005) Age, size and growth of the southern crested newt Triturus karelinii (Strauch 1870) in a population from Bozdag (western Turkey). Amphibia-Reptilia 26:223-230

Oromi N, Sanuy D, Sinsch U (2012) Altitudinal variation of demographic life-history traits does not mimic latitudinal variation in natterjack toads (Bufo calamita). Zoology 115:30-37

Rozenblut B, Ogielska M (2005) Development and growth of long bones in European water frogs (Amphibia: Anura: Ranidae), with remarks on age determination. J Morphol 265:304-317

Sagor ES, Ouellet M, Barten E, Green DM (1998) Skeletochronology and geographic variation in age structure in the wood frog, Rana sylvatica. J Herpetol 32:469-474 
Sinsch U, Marangoni F, Oromi N, Leskovar C, Sanuy D, Tejedo M (2010) Proximate mechanisms determining size variability in natterjack toads. J Zool 281:272-281

Tanaka-Ueno T, Matsui M, Chen SL, Tanaka O, Ota H (1998) Phylogenetic relationships of brown frogs from Taiwan and Japan assessed by mitochondrial cytochrome $b$ gene sequences (Rana: Ranidae). Zool Sci 15:283-288

Tsiora A, Kyriakopoulou-Sklavounou P (2002) A skeletochronological study of age and growth in relation to adult size in the water frog Rana epeirotica. Zoology 105:55-60

von Bertalanffy L (1938) A quantitative theory of organic growth. Hum Biol 10:81-213

von Bertalanffy L (1957) Quantitative laws in metabolism and growth. Q Rev Biol 32:217-231

Zhang LX, Lu X (2012) Amphibians live longer at higher altitudes but not at higher latitudes. Biol J Linn Soc 106:623-632

Zhang LX, Lu X (2013) Sexual size dimorphism in anurans: ontogenetic determination revealed by an across-species comparison. Evol Biol 40:84-91

Zhang LX, Ma X, Jiang J, Lu X (2012) Stronger condition dependence in female size explains altitudinal variation in sexual size dimorphism of a Tibetan frog. Biol J Linn Soc 107:558-565

Zug GR (1993) Herpetology: an introductory biology of amphibians and reptiles. Academic, San Diego

doi:10.1186/s40555-014-0062-y

Cite this article as: Hsu et al:: Altitudinal variation in body size and age structure of the Sauter's frog Rana sauteri in Taiwan. Zoological Studies 2014 53:62.

\section{Submit your manuscript to a SpringerOpen ${ }^{\circ}$ journal and benefit from:}

- Convenient online submission

- Rigorous peer review

- Immediate publication on acceptance

- Open access: articles freely available online

- High visibility within the field

- Retaining the copyright to your article

Submit your next manuscript at $\gg$ springeropen.com 